\title{
Systematic Adverse Drug Reaction Monitoring of Patients Under Newer Antiepileptic Drugs Using Routine Clinical Data of Inpatients
}

\author{
Annika Hilgers $^{1,2,3} \cdot$ Marion Schaefer $^{3}$
}

Published online: 25 May 2016

(C) The Author(s) 2016. This article is published with open access at Springerlink.com

\begin{abstract}
Background Based on data of clinical trials, new agents are receiving approval to the pharmaceutical market, for which information concerning safety issues under real-life conditions is not yet available.

Objectives The aim was to evaluate the tolerability of newer antiepileptic drugs (AEDs), such as topiramate, levetiracetam, zonisamide, pregabalin, extended-release oxcarbazepine, lacosamide and eslicarbazepine, under reallife conditions by means of an assessment of routine clinical data of inpatients.

Method Over 2.75 years data of all inpatients receiving one of the newer AEDs were documented. Occurring adverse drug reactions (ADRs) were classified according to the WHO-UMC Causality Assessment concerning their likely relationship to the prescribed AEDs. For each AED,
\end{abstract}

Electronic supplementary material The online version of this article (doi:10.1007/s40801-016-0077-2) contains supplementary material, which is available to authorized users.

Annika Hilgers

annika.hilgers@evkb.de

1 Ev. Krankenhaus Bielefeld gGmbH, Bethesdaweg 10, 33617 Bielefeld, Germany

2 Epilepsiezentrum Bethel, Krankenhaus Mara gGmbH, 33617 Bielefeld, Germany

3 Charité Universitätsmedizin Berlin, Institut für klinische Pharmakologie, 10115 Berlin, Germany the total number of patients without and with ADRs, assessed as at least possibly related to the particular drug, was calculated and corresponding incidences compared with reference data provided in the Summary of Product Characteristics (SmPC). For statistical evaluation Spearman correlation $\left(r_{\mathrm{s}}\right)$, estimated relative risk and logistic regression analysis were used.

Results In total, the data of 562 patients were assessed, of which $90 \%$ received up to six different AEDs. The proportion of off-label use with regard to dosage varied between 6.4 and $64.7 \%$. Levetiracetam and oxcarbazepine as an extended-release formulation were most commonly used, and levetiracetam showed the best tolerance. By using logistic regression, the occurrence of ADRs was significantly associated with the number of AEDs $(p<0.001)$ as well as the defined daily doses $(p=0.003)$. In total, ADRs of AEDs were documented for 318 patients $(56.6 \%)$. The most common referred to electrolyte imbalance, e.g., low sodium $(n=79,14.1 \%)$ and potassium $(n=25,4.4 \%)$ levels, the central nervous system, including dizziness $(n=61,10.9 \%)$, disturbed vision $(n=47,8.4 \%)$, fatigue $(n=40,7.1 \%)$, nystagmus $(n=36,6.4 \%)$ and ataxia $(n=29,5.2 \%)$, or cognitive deficits, especially disturbance of speech $(n=37,6.6 \%)$, memory impairment $(n=36,6.4 \%)$ and mental slowing $(n=32,5.7 \%)$. By comparing the assessed ADR incidences with specification data, for some ADRs, a probable underestimation by the SmPC of respective risk could be assumed.

Conclusion During inpatient treatment, valuable data are generated, which are currently rarely utilized for pharmacoepidemiologic or pharmacovigilance purposes. A systematic evaluation of these data can increase the probability of detecting ADRs and can promote real-liferelated drug surveillance. 


\section{Key Points}

Summary of Product Characteristics data may underestimate the risk of adverse drug reactions.

Continuous tolerability and safety surveillance is necessary to align approval data with real-life experience.

Frequent risk evaluation of drugs by means of routine clinical data could provide a new quality of drug surveillance.

\section{Introduction}

Based on submitted quality, efficacy and safety data, dozens of new agents are receiving approval to the pharmaceutical market every year. Despite their promising advantage to medical care, at the time of approval, there can be no certainty that these drugs are completely safe [1]. Information about specific population groups can frequently be assumed to be missing as well as data about rare adverse drug reactions (ADRs) or drug interactions. It is therefore necessary to establish methods of large-scale post-marketing surveillance to gather real-life data especially with regard to safety issues. In most countries a spontaneous reporting system (SRS) for collecting data of suspected ADRs is used. Reported data are assessed by the responsible authority in a global database, which thus contains a vast data pool of ADRs relating to a wide range of drugs, in support of its main objective of generating signals of unknown, rare or serious ADRs [2-4]. This is a very cost-effective method. However, this kind of drug safety monitoring also has many limitations, the most frequently mentioned being the subject of underreporting. The mentioned reasons for this are manifold, including lack of time, large effort, fear of being prosecuted, unawareness of the requirement to report or the estimation that a particular ADR is not worth noting [3-5]. Also, SRSs are often believed to be exclusively designed for detecting rare and serious ADRs, but for general drug safety, the monitoring of all undesirable reactions is necessary [4]. For the most accurate relative risk (RR) assessment, exact data of application or drug utilization is required, which, however, is only available by approximation. Thus, an SRS has not got the impact to determine the prevalence rate of a specific ADR reliably and bears a risk of delay in signal detection.

In the case of diseases requiring lifelong treatment, more detailed knowledge about the efficacy and tolerability of a drug, attention to ADRs as well as awareness of patients' needs are necessary to achieve the best therapeutic outcome. For epilepsy, as one of these diseases, the occurrence of ADRs has been shown to have an important influence on patients' quality of life [6-9]. Approximately $20 \%$ of all patients with epilepsy, in the case of refractory epilepsy, even about $50 \%$, are on polytherapy, bearing an increased risk for ADRs and drug interactions [10-13]. Many of these patients have tried most of the available drugs and are therefore a target group for new treatment options aimed at reducing seizure frequency while maintaining or even optimizing tolerability. Especially in patients suffering from seizure recurrence, optimizing therapy can be a balancing act between increasing the drug dosage to maximize the therapeutic effect and running the risk of ADRs [14, 15]. Over the past 25 years, more than 15 new antiepileptic drugs (AEDs) with modified acting mechanisms and/or side effect profiles have become available for epilepsy treatment, resulting in a major challenge for health professionals and post-marketing surveillance in respect of specified knowledge about tolerability and drug interaction. Such a level of competence can hardly be generated by relying only upon a tool like an SRS for monitoring drug safety. In fact, long-term supervision of medicated patients, increased sensitivity towards recognizing accumulation of specific ADRs and deriving remedial measures from these observations are recommended as vital for a comprehensive risk-benefit evaluation [14]. Accordingly, the systematic assessment and evaluation of routine inpatient data was assumed to be one way of obtaining this relevant knowledge and was therefore investigated in this survey.

\section{Methods}

\subsection{Data Collection}

Between May 2008 and December 2010, an in-house pharmacist attended the Consultants' ward round once a week on four different wards of the Bethel Epilepsy Centre, Bielefeld, Germany, a tertiary reference center for epilepsy. All information taken as part of clinical routine during the ward round was documented in the patients' chart as usual and, for later digitalization, concurrently transcribed to an adjusted record form by the pharmacist. For every patient a new record form was used for each week. All inpatients receiving one of the newer AEDs, i.e., topiramate (TPM), levetiracetam (LEV), zonisamide (ZNS), pregabalin (PGB), extended-release oxcarbazepine [OXC(ER)], lacosamide (LCM) and eslicarbazepine (ESL), were included. Documented data comprised the specific drug, all AEDs in use, corresponding daily dosages and serum levels, if available, age, gender, concomitant 
medication, patient and actual case number. In addition, all patient-reported and medically diagnosed ADRs were documented in an unstructured format, and for each one, the current causality concerning the administered AEDs was assessed by interprofessional exchange (i.e., physician, pharmacist, nursing staff). To this end, the temporal pattern of association between its occurrence and change of medication and all available information concerning concomitant disorders, diseases or medication were taken into account. For the classification of causality, the WHO-UMC Causality Categories were used (see the electronic supplementary material, Online Resource 1) [16]. Any severe or unknown suspected ADRs were immediately reported via the SRS to the responsible regulatory authority.

\subsection{Data Entry}

All relevant data were recorded by the pharmacist in an internal database, using IBM SPSS for Windows 20.0. Patient data were documented by assigning an individual patient number, case number, gender, age and date of observation. In order to enable the evaluation, the initially documented ADRs were coded numerically according to the system organ classes (SOCs) of the MedDRA (Medical Dictionary for Regulatory Activities) terminology, and the specific symptom. Also, corresponding causality categories were entered numerically. For every documented ADR and week, a single data set containing patient details, medication, daily dosage and causality category for every given AED was generated. Where the same ADR was documented more than once for one patient, the first documented observation and accordingly the one with the lowest AED dosages was included for analysis only. For patients without ADRs, the highest AED dosage was considered. To rule out possible input errors, the data were entered twice at different times. Asserted discrepancies were clarified by re-checking the record forms.

\subsection{Data Evaluation}

Demographic and clinical characteristics of the patients were evaluated by using the first documented contact after hospitalization. For every newer AED, the total number of patients without and with ADRs, assessed with at least possible causality, and the corresponding dosages were calculated. Additionally, the same analysis was performed including only data sets of patients being treated off-label with regard to the maximum recommended daily dosage in the Summary of Product Characteristics (SmPC). In both analyses, every patient was included only once. Furthermore, for every AED, the incidence of the respective ADR was determined with reference to the number of patients experiencing this ADR while taking the particular AED divided by the total number of patients where this AED was part of the therapy. All estimated incidence rates were compared with the respective data provided in the SmPC of each AED [17-23]. The correlation between the number of AEDs and the total drug load, calculated as sum of the defined daily doses (DDDs), was determined by Spearman correlation. For assessing the impact of number of AEDs and sum of DDDs on the occurrence of ADR, logistic regression was used.

Concerning tolerability of each AED, the RR of ADR occurrence was calculated. For this purpose, the data of LEV were used as the reference, as being the most frequently applied AED in this survey, the first recommended for treatment of focal epilepsy out of this selection and also proven as well tolerated [24-28].

\section{Results}

In total, data of 562 cases were assessed, which equals around one quarter of the total number of in-house patients on the attended wards in the same time period. The corresponding patients' characteristics, length of stay and number of AEDs in concomitant usage [mean, median and standard deviation (SD)] are summarized in Table 1. For further specification of the antiepileptic therapy, the number and percentage distribution of patients receiving antiepileptic monotherapy versus polytherapy of up to six different AEDs were evaluated on the basis of each initially documented observation per patient. Hence, 57 patients $(10.1 \%)$ were on monotherapy, 192 patients (34.2\%) were treated with two different AEDs, 205 patients $(36.5 \%)$ with three, $88(15.7 \%)$ with four, 19 $(3.4 \%)$ with five and just one patient $(0.2 \%)$ with six. The number of AEDs correlated significantly with the total drug load as sum of DDDs $\left(r_{\mathrm{s}}=0.661, p<0.001\right)$. The mean drug load ( \pm SD) per patient increased with an increasing number of AEDs from $1.15 \pm 0.60$ in patients on monotherapy to $2.42 \pm 0.98$ in patients on two concomitant AEDs, $3.33 \pm 1.33$ in those on three, $4.50 \pm 1.35$ in those on four and $5.56 \pm 1.28$ in those on five or six.

In monotherapy, as well as in a combination of two different AEDs, OXC(ER) and LEV were the ones most commonly used. This is the case for more than $40 \%$ of the patients. For further information concerning the percentage of each AED in antiepileptic polytherapy see Fig. 1. LEV and $\mathrm{OXC}(\mathrm{ER})$ were further the most frequently used at all, with applications documented for 367 and 183 patients, respectively. For TPM and LCM, the data of 109 and 102 patients were assessed, whereas ZNS (68 patients), PGB (61 patients) and ESL (17 patients) were a less frequently used component of the antiepileptic therapy. 
Table 1 Patients'

characteristics $^{\mathrm{a}}$ of 562 in-house patients treated at the tertiary reference center for epilepsy who were receiving at least one of the newer AEDs

\begin{tabular}{|c|c|c|c|c|c|c|c|}
\hline & $N$ & Total $(\%)$ & Mean & Median & $\mathrm{SD}$ & Min. & Max. \\
\hline \multicolumn{8}{|l|}{ Gender } \\
\hline Male & 293 & 52.1 & & & & & \\
\hline Female & 269 & 47.9 & & & & & \\
\hline \multicolumn{8}{|l|}{ Epilepsy syndrome } \\
\hline Focal & 446 & 79.4 & & & & & \\
\hline Generalized & 83 & 14.8 & & & & & \\
\hline Focal + generalized & 24 & 4.3 & & & & & \\
\hline Non-epileptic disorder ${ }^{\mathrm{b}}$ & 9 & 1.6 & & & & & \\
\hline Age (years) & 562 & & 37.2 & 36.0 & 14.6 & 16.0 & 89.0 \\
\hline Length of stay (days) & 562 & & 60.6 & 51.0 & 38.7 & 6.0 & 238.0 \\
\hline No. of AEDs per patient & 562 & & 2.64 & 3.00 & 1.00 & 1.00 & 6.00 \\
\hline Drug load of AEDs (DDD) ${ }^{c}$ & 562 & & 3.14 & 3.02 & 1.53 & 0.25 & 10.82 \\
\hline
\end{tabular}

$A E D$ antiepileptic drug, $D D D$ defined daily dose, $S D$ standard deviation

${ }^{\text {a }}$ Calculated by including every first documented observation of each patient

b Differential diagnosis of a paroxysmal non-epileptic disorder obtained during hospitalization

${ }^{c}$ Sum of DDD according to the WHO DDD list

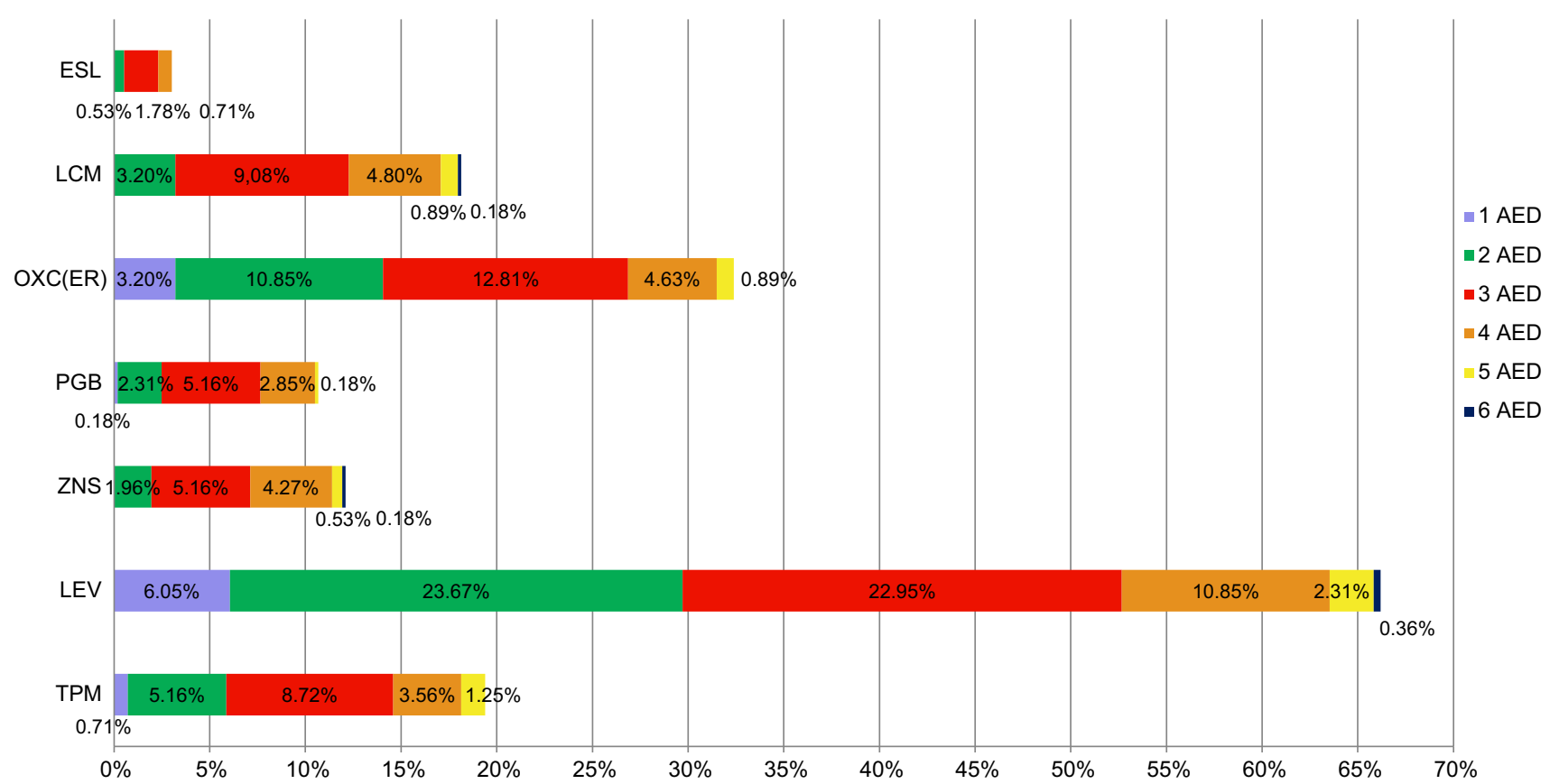

Fig. 1 Percentage of patients treated with the respective AED, stratified by monotherapy and the different kinds of polytherapy (left to right). Total percentage of patients taking respective drug either as monotherapy or part of polytherapy: LEV $66.19 \%$, OXC(ER) $32.38 \%$, TPM $19.4 \%$, LCM $18.15 \%$, ZNS $12.1 \%$, PGB $10.68 \%$,

In total, ADRs of AEDs were documented for 318 patients $(56.6 \%)$. Logistic regression indicated that the occurrence of ADRs was significantly associated with the number of AEDs in polytherapy regime $(p<0.001)$ as well as the total drug load as sum of DDDs $(p=0.003)$, whereas each predictor was analyzed separately. and ESL $3.02 \%$. AED antiepileptic drug, ESL eslicarbazepine, $L C M$ lacosamide, $L E V$ levetiracetam, $O X C(E R)$ oxcarbazepine extendedrelease formulation, $P G B$ pregabalin, TPM topiramate, ZNS zonisamide

For each of the focused AEDs, the number of cases without and with an ADR of at least possible causality and corresponding dosages are listed in Table 2. For none of these AEDs the sum of percentage of cases without and with possibly related ADRs achieved $100 \%$. The differences, ranging from 4 to $15 \%$, represent ADRs assessed as 
Table 2 Patients without and with at least possibly related ADRs, stratified by the respective AEDs, including details of particular daily dosages

\begin{tabular}{|c|c|c|c|c|c|c|c|c|c|}
\hline & \multirow[t]{2}{*}{$N$} & \multirow[t]{2}{*}{$\operatorname{Total}^{\mathrm{a}}(\%)$} & \multirow[t]{2}{*}{$\mathrm{RR}^{\mathrm{b}}$} & \multirow[t]{2}{*}{ CI } & \multicolumn{5}{|c|}{ Daily dosage (mg) } \\
\hline & & & & & Mean & Median & SD & Min. & Max. \\
\hline \multicolumn{10}{|l|}{ LEV } \\
\hline Without ADR & 203 & 55.3 & {$[1.00]$} & & 2596 & 3000 & 1107 & 250 & 6000 \\
\hline With possible ADR & 120 & 32.7 & & & 2465 & 2500 & 1096 & 250 & 7000 \\
\hline \multicolumn{10}{|l|}{ PGB } \\
\hline Without ADR & 26 & 42.6 & 1.31 & $0.89-1.93$ & 487 & 600 & 187 & 75 & 750 \\
\hline With possible ADR & 28 & 45.9 & & & 321 & 275 & 194 & 75 & 750 \\
\hline \multicolumn{10}{|l|}{ ZNS } \\
\hline Without ADR & 26 & 38.2 & 1.40 & $0.98-2.02$ & 256 & 250 & 164 & 50 & 600 \\
\hline With possible ADR & 32 & 47.1 & & & 338 & 300 & 148 & 100 & 600 \\
\hline \multicolumn{10}{|l|}{$\mathrm{OXC}(\mathrm{ER})$} \\
\hline Without ADR & 73 & 39.9 & 1.57 & $1.26-1.95$ & 1715 & 1800 & 677 & 450 & 3850 \\
\hline With possible ADR & 97 & 53.0 & & & 1646 & 1800 & 530 & 450 & 3000 \\
\hline \multicolumn{10}{|l|}{ LCM } \\
\hline Without ADR & 37 & 36.3 & 1.63 & $1.24-2.13$ & 326 & 350 & 144 & 50 & 600 \\
\hline With possible ADR & 55 & 53.9 & & & 269 & 250 & 139 & 50 & 600 \\
\hline \multicolumn{10}{|l|}{ TPM } \\
\hline Without ADR & 31 & 28.4 & 1.97 & $1.56-2.47$ & 223 & 150 & 203 & 25 & 800 \\
\hline With possible ADR & 65 & 59.6 & & & 213 & 200 & 119 & 50 & 500 \\
\hline \multicolumn{10}{|l|}{ ESL } \\
\hline Without ADR & 2 & 11.8 & 2.30 & $1.75-3.02$ & 1800 & 1800 & 849 & 1200 & 2400 \\
\hline With possible ADR & 14 & 82.4 & & & 1514 & 1600 & 501 & 800 & 2400 \\
\hline
\end{tabular}

$A E D$ antiepileptic drug, $A D R$ adverse drug reaction, $C I$ confidence interval, $E S L$ eslicarbazepine, $L C M$ lacosamide, $L E V$ levetiracetam, $O X C(E R)$ oxcarbazepine extended-release formulation, $P G B$ pregabalin, $R R$ relative risk for the occurrence of possibly related ADRs compared with the occurrence of these under levetiracetam, $S D$ standard deviation, TPM topiramate, ZNS zonisamide

${ }^{\text {a }}$ For calculation, the total number of documented cases per AED was used; the missing percentage up to $100 \%$ fall upon ADRs assessed as unlikely, conditional or not causally linked to the particular AED

${ }^{b}$ For calculation of RR, patients taking both of the specifically compared AEDs were excluded unlikely, conditional or not causally linked to the particular AED. In the case of TPM, this applied to 13 patients, for LEV to 44 , PGB to seven, ZNS to ten, OXC(ER) to 13 , LCM to ten and ESL to just one patient.

By referring exclusively to the overall tolerability, LEV emerged as best tolerated. The calculated RRs of ADR occurrence per AED compared with LEV, which was set as reference, ranged between 1.31 and 2.30 , whereas again just the total number of possibly related ADRs was taken into account, not the clinical relevance of every single ADR nor other tolerability influencing factors.

By means of the maximum applied dosages (Table 2), it becomes apparent that in some cases the maximum applied AED dosage exceeded the maximum permissible dosage according to the particular SmPC [17-23]. For LCM, that dosage was specified as $400 \mathrm{mg}$ per day, for TPM and $\mathrm{ZNS}$, as $500 \mathrm{mg} /$ day each, and for $\mathrm{PGB}$, as $600 \mathrm{mg} /$ day; for ESL, OXC(ER) and LEV, the maximum approved dosage was determined as 1200, 2400 and $3000 \mathrm{mg} /$ day, respectively. The proportion of off-label usage concerning the maximum recommended daily dosage in the SmPC varied between 6.4 and $64.7 \%$ with regard to the total number of patients the respective AED was part of therapy. For further differentiation, the corresponding data of every single AED, with and without ADR, is summarized in Table 3. Comparing the calculated RR for each AED used off-label to its application as recommended by the SmPC revealed no relevant risk change. Though, the number of patients for these evaluations was small.

Concerning the documented ADRs, the most common were related to electrolyte imbalance, e.g., low sodium $(n=79,14.1 \%)$ and potassium $(n=25,4.4 \%)$ levels, the central nervous system, including dizziness $(n=61$, $10.9 \%)$, disturbed vision $(n=47,8.4 \%)$, fatigue $(n=40,7.1 \%)$, nystagmus $(n=36,6.4 \%)$ and ataxia ( $n=29,5.2 \%$ ), or cognitive deficits, especially disturbance of speech $(n=37,6.6 \%)$, memory impairment $(n=36,6.4 \%)$ and mental slowing $(n=32,5.7 \%)$. In 24 patients $(4.3 \%)$, the observed ADRs were considered as severe, rare, very distinctive or currently unknown and 
Table 3 Patients under offlabel use concerning dose, without and with at least possibly related ADRs, stratified by the respective AEDs, including details of particular daily dosages

\begin{tabular}{|c|c|c|c|c|c|c|c|c|c|}
\hline & \multirow[t]{2}{*}{$N$} & \multirow[t]{2}{*}{$\operatorname{Total}^{\mathrm{a}}(\%)$} & \multirow[t]{2}{*}{$\mathrm{RR}$} & \multirow[t]{2}{*}{$\mathrm{CI}$} & \multicolumn{5}{|c|}{ Daily dosage (mg) } \\
\hline & & & & & Mean & Median & SD & Min. & Max. \\
\hline \multicolumn{10}{|l|}{ ТPM } \\
\hline Off-label use & 7 & 6.4 & & & & & & & \\
\hline Without ADR & 4 & 3.7 & 0.49 & $0.16-1.54$ & 638 & 600 & 111 & 550 & 800 \\
\hline With possible ADR & 2 & 1.8 & & & 650 & 650 & 71 & 600 & 700 \\
\hline \multicolumn{10}{|l|}{ LCM } \\
\hline Off-label use & 18 & 17.6 & & & & & & & \\
\hline Without ADR & 8 & 7.8 & 0.84 & $0.50-1.40$ & 513 & 500 & 58 & 450 & 600 \\
\hline With possible ADR & 8 & 7.8 & & & 500 & 500 & 53 & 450 & 600 \\
\hline \multicolumn{10}{|l|}{ LEV } \\
\hline Off-label use & 91 & 24.8 & & & & & & & \\
\hline Without ADR & 50 & 13.6 & 0.95 & $0.68-1.33$ & 3945 & 4000 & 408 & 3500 & 6000 \\
\hline With possible ADR & 27 & 7.4 & & & 4102 & 4000 & 701 & 3500 & 7000 \\
\hline \multicolumn{10}{|l|}{ PGB } \\
\hline Off-label use & 6 & 9.8 & & & & & & & \\
\hline Without ADR & 3 & 4.9 & 0.96 & $0.42-2.24$ & 725 & 750 & 43 & 675 & 750 \\
\hline With possible ADR & 3 & 4.9 & & & 708 & 700 & 38 & 675 & 750 \\
\hline \multicolumn{10}{|l|}{ OXC(ER) } \\
\hline Off-label use & 20 & 10.9 & & & & & & & \\
\hline Without ADR & 8 & 4.4 & 1.02 & $0.68-1.52$ & 2994 & 3000 & 401 & 2550 & 3850 \\
\hline With possible ADR & 11 & 6.0 & & & 2832 & 2700 & 316 & 2500 & 3600 \\
\hline \multicolumn{10}{|l|}{ ESL } \\
\hline Off-label use & 11 & 64.7 & & & & & & & \\
\hline Without ADR & 1 & 5.9 & 1.03 & $0.78-1.36$ & 2400 & 2400 & & 2400 & 2400 \\
\hline With possible ADR & 9 & 52.9 & & & 1822 & 1600 & 353 & 1600 & 2400 \\
\hline \multicolumn{10}{|l|}{ ZNS } \\
\hline Off-label use & 7 & 10.3 & & & & & & & \\
\hline Without ADR & 2 & 2.9 & 1.21 & $0.66-2.23$ & 600 & 600 & 0 & 600 & 600 \\
\hline With possible ADR & 4 & 5.9 & & & 588 & 600 & 25 & 550 & 600 \\
\hline
\end{tabular}

$A E D$ antiepileptic drug, $A D R$ adverse drug reaction, $C I$ confidence interval, $E S L$ eslicarbazepine, $L C M$ lacosamide, $L E V$ levetiracetam, $O X C(E R)$ oxcarbazepine extended-release formulation, $P G B$ pregabalin, $R R$ relative risk for the occurrence of possibly related ADRs comparing off-label use concerning dose to the particular applications of the same drug used on-label, i.e., according to the recommended dosage by the Summary of Product Characteristics, SD standard deviation, TPM topiramate, ZNS zonisamide

${ }^{\text {a }}$ For calculation, the total number of documented cases per AED was used therefore reported via the SRS to the responsible regulatory authority. Among these reports were one case of an arrhythmia absoluta under the combination of LCM and LEV as a potentially life-threatening ADR, three of suicidal ideation (two under LEV, one under the combination of OXC(ER)/LCM), three of myoklonia [two under OXC(ER), one under LEV], two of peripheral edema under $\mathrm{OXC}(\mathrm{ER})$, one of paresthesia under LEV, one of anorexia under TPM and one case of anxiety under LEV.

For comparing the frequency of occurrence of particular ADRs in relation to the information mentioned in the SmPC, the incidence of the ADR was calculated for each
AED separately. The detailed results are shown in Table 4. Although, SmPC data express a very rough classification for ADR frequency by using categories differing by one power of ten only, e.g., $\geq 0.1 \%$ for an uncommon and $\geq 10 \%$ for a very common occurrence, for some registered ADRs probable underestimation was assumed. This, for example, was apparent in the case of cognitive impairment related to TPM and electrolyte imbalance concerning potassium under therapy with an carbonic anhydrase (CA) inhibitor (i.e., TPM, ZNS) or sodium level by application of dibenzazepine anticonvulsants (i.e., OXC, ESL). 
Table 4 Incidence rates of all ADRs, assessed as at least possibly related to the antiepileptic drug, compared with corresponding frequency data by the SmPC (nonexhaustive list; occurred ADRs mentioned only)

\begin{tabular}{|c|c|c|c|c|c|c|c|c|c|c|c|c|c|}
\hline \multicolumn{2}{|l|}{ TPM } & \multicolumn{2}{|l|}{ LEV } & \multicolumn{2}{|l|}{ PGB } & \multicolumn{2}{|l|}{ ZNS } & \multicolumn{2}{|c|}{$\mathrm{OXC}(\mathrm{ER})$} & \multicolumn{2}{|l|}{ LCM } & \multicolumn{2}{|l|}{ ESL } \\
\hline Obs. & SmPC & Obs. & SmPC & Obs. & SmPC & Obs. & SmPC & Obs. & SmPC & Obs. & SmPC & Obs. & SmPC \\
\hline
\end{tabular}

Metabolism and nutrition disorders

Weight gain

$\begin{array}{llllllllll}N & & 3 & & 7 & & & & & \\ \% & 0.8 & \geq 0.1 & 11.3 & \geq 1 & \text { N/A } & 1.1 & \text { N/A } & \text { N/A }\end{array}$

Weight loss

$\begin{array}{lll}N & 9 & 2\end{array}$

$\begin{array}{llll}\% & 8.2 & \geq 10 & 0.5\end{array}$

Decreased appetite/anorexia

$\begin{array}{lll}N & 5 & 5\end{array}$

$\% \quad 4.5 \quad \geq 1 \quad 1.4 \quad \geq 1$

Hypokalemia

$\begin{array}{lllll}N & 11 & & 3 \\ \% & 10.1 & \geq 0.1 & 0.8 & \text { N/A }\end{array}$

Hyponatremia

$\begin{array}{lllll}N & & 3 & & 1 \\ \% & \text { N/A } & 0.8 & \geq 0.01 & 1.6\end{array}$

Psychiatric disorders

Sleep disturbance/insomnia

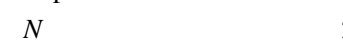

$\begin{array}{rr}\% & \geq 1 \\ \text { Nervousness/agitation }\end{array}$

$$
\begin{aligned}
& \begin{array}{ll}
N & 1 \\
\% & 0.9 \quad \geq 1
\end{array} \\
& \% \quad 0.9
\end{aligned}
$$

Irritability

$$
\begin{array}{lll}
N & 2 & 10
\end{array}
$$$$
\begin{array}{lllll}
\% & 1.8 & \geq 1 & 2.7 & \geq 1
\end{array}
$$

Aggressive reaction

$$
\begin{array}{lll}
N & 2
\end{array}
$$$$
\% \quad 1.8 \quad \geq 1 \quad 3.0
$$

Anxiety

$$
N
$$

$\%$

$+1$

Listlessness/apathy

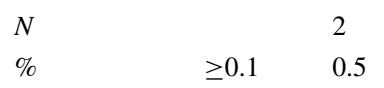

Mood swings/depressed mood

$$
\begin{array}{lll}
N & 2 & 8
\end{array}
$$$$
\% \quad 1.8 \quad \geq 10 \quad 2.2 \quad \geq 1
$$

Confusion

$$
N
$$

\begin{tabular}{|c|c|c|c|c|c|c|c|c|c|c|c|c|c|c|}
\hline$N$ & 5 & & 25 & & 5 & & 6 & & 12 & & 6 & & 2 & \\
\hline$\%$ & 4.5 & $\geq 10$ & 6.8 & $\geq 10$ & 8.1 & $\geq 10$ & 9.0 & $\geq 10$ & 6.6 & $\geq 10$ & 5.8 & $\geq 1$ & 11.8 & $\geq 10$ \\
\hline \multicolumn{15}{|c|}{ Dizziness } \\
\hline$N$ & 5 & & 23 & & 7 & & 5 & & 24 & & 25 & & 5 & \\
\hline$\%$ & 4.5 & $\geq 10$ & 6.3 & $\geq 1$ & 11.3 & $\geq 1$ & 7.5 & $\geq 10$ & 13.3 & $\geq 10$ & 24.3 & $\geq 10$ & 29.4 & $\geq 10$ \\
\hline
\end{tabular}$$
\%
$$

Suicidal ideation

$$
\begin{array}{lllll}
N & 1 & & 4 \\
\% & 0.9 & \geq 0.1 & 1.1
\end{array}
$$

Nervous system disorders

Fatigue/tiredness 
Table 4 continued

\begin{tabular}{|c|c|c|c|c|c|c|c|c|c|c|c|c|c|c|}
\hline & \multicolumn{2}{|l|}{ TPM } & \multicolumn{2}{|l|}{ LEV } & \multicolumn{2}{|l|}{ PGB } & \multicolumn{2}{|l|}{ ZNS } & \multicolumn{2}{|c|}{ OXC(ER) } & \multicolumn{2}{|l|}{ LCM } & \multicolumn{2}{|l|}{ ESL } \\
\hline & Obs. & SmPC & Obs. & SmPC & Obs. & $\mathrm{SmPC}$ & Obs. & SmPC & Obs. & SmPC & Obs. & SmPC & Obs. & $\mathrm{SmPC}$ \\
\hline \multicolumn{15}{|c|}{ Nystagmus } \\
\hline$N$ & 4 & & 10 & & 5 & & 2 & & 13 & & 19 & & 4 & \\
\hline$\%$ & 3.6 & $\geq 1$ & 2.7 & N/A & 8.1 & $\geq 0.1$ & 3.0 & $\geq 1$ & 7.2 & $\geq 1$ & 18.4 & $\geq 1$ & 23.5 & $\geq 0.1$ \\
\hline \multicolumn{15}{|c|}{ Tremor } \\
\hline$N$ & 2 & & 17 & & 3 & & 2 & & 3 & & 8 & & 1 & \\
\hline$\%$ & 1.8 & $\geq 1$ & 4.6 & $\geq 1$ & 4.8 & $\geq 1$ & 3.0 & $\geq 1$ & 1.7 & $\geq 1$ & 7.8 & $\geq 1$ & 5.9 & $\geq 1$ \\
\hline \multicolumn{15}{|c|}{ Balance disorder/ataxia } \\
\hline$N$ & 3 & & 10 & & 2 & & 2 & & 12 & & 11 & & 2 & \\
\hline$\%$ & 2.7 & $\geq 1$ & 2.7 & $\geq 1$ & 3.2 & $\geq 1$ & 3.0 & $\geq 10$ & 6.6 & $\geq 1$ & 10.7 & $\geq 1$ & 11.8 & $\geq 1$ \\
\hline \multicolumn{15}{|c|}{ Disturbance in concentration/attention } \\
\hline$N$ & 16 & & 3 & & & & 2 & & 2 & & 1 & & & \\
\hline$\%$ & 14.7 & $\geq 1$ & 0.8 & $\geq 0.1$ & & $\geq 1$ & 3.0 & $\geq 1$ & 1.1 & $\geq 1$ & 1.0 & $\geq 1$ & & $\geq 1$ \\
\hline \multicolumn{15}{|c|}{ Memory impairment } \\
\hline$N$ & 25 & & 11 & & 2 & & 6 & & 3 & & 2 & & & \\
\hline$\%$ & 22.9 & $\geq 1$ & 3.0 & $\geq 0.1$ & 3.2 & $\geq 1$ & 9.0 & $\geq 10$ & 1.7 & $\geq 1$ & 1.9 & $\geq 1$ & & $\geq 0.1$ \\
\hline \multicolumn{15}{|c|}{ Disturbance of speech } \\
\hline$N$ & 31 & & 4 & & & & 3 & & 4 & & 2 & & & \\
\hline$\%$ & 28.4 & $\geq 1$ & 1.1 & N/A & & $\geq 0.1$ & 4.4 & $\geq 1$ & 2.2 & N/A & 1.9 & $\geq 1$ & & $\geq 0.1$ \\
\hline \multicolumn{15}{|c|}{ Mental slowing/bradyphrenia } \\
\hline$N$ & 17 & & 10 & & 1 & & 8 & & 4 & & 4 & & & \\
\hline$\%$ & 15.6 & $\geq 1$ & 2.7 & N/A & 1.6 & $\geq 0.1$ & 11.9 & $\geq 1$ & 2.2 & N/A & 3.9 & $\geq 1$ & & N/A \\
\hline \multicolumn{15}{|c|}{ Headache } \\
\hline$N$ & 1 & & 6 & & 1 & & & & 7 & & 4 & & 1 & \\
\hline$\%$ & 0.9 & N/A & 1.6 & $\geq 10$ & 1.6 & $\geq 10$ & & N/A & 3.9 & $\geq 10$ & 3.9 & $\geq 10$ & 5.9 & $\geq 1$ \\
\hline Dys & & & & & & & & & & & & & & \\
\hline$N$ & & & 1 & & 1 & & & & & & & & & \\
\hline$\%$ & & $\geq 1$ & 0.3 & N/A & 1.6 & $\geq 0.1$ & & N/A & & N/A & & N/A & & N/A \\
\hline Pare & esia & & & & & & & & & & & & & \\
\hline$N$ & 3 & & 2 & & & & & & & & & & & \\
\hline$\%$ & 2.7 & $\geq 10$ & 0.5 & N/A & & $\geq 1$ & & $\geq 1$ & & N/A & & $\geq 1$ & & $\geq 0.1$ \\
\hline Eye & orders & & & & & & & & & & & & & \\
\hline Blur & vision & plopia & & & & & & & & & & & & \\
\hline$N$ & 6 & & 13 & & 5 & & 5 & & 23 & & 17 & & 4 & \\
\hline$\%$ & 5.5 & $\geq 1$ & 3.5 & $\geq 0.1$ & 8.1 & $\geq 1$ & 7.5 & $\geq 10$ & 12.6 & $\geq 10$ & 16.5 & $\geq 10$ & 23.5 & $\geq 1$ \\
\hline Ear & labyri & disord & & & & & & & & & & & & \\
\hline Tinn & & & & & & & & & & & & & & \\
\hline$N$ & 1 & & 1 & & & & & & & & & & & \\
\hline$\%$ & 0.9 & $\geq 1$ & 0.3 & N/A & & N/A & & N/A & & N/A & & $\geq 1$ & & $\geq 0.1$ \\
\hline Gast & intestin & disorder & & & & & & & & & & & & \\
\hline Naus & /vomiti & & & & & & & & & & & & & \\
\hline$N$ & 3 & & 4 & & 1 & & & & 13 & & 15 & & 2 & \\
\hline$\%$ & 2.7 & $\geq 10$ & 1.1 & $\geq 1$ & 1.6 & $\geq 1$ & & $\geq 1$ & 7.2 & $\geq 10$ & 14.6 & $\geq 10$ & 11.8 & $\geq 1$ \\
\hline Diar & & & & & & & & & & & & & & \\
\hline$N$ & 1 & & 1 & & & & & & & & 1 & & & \\
\hline$\%$ & 0.9 & $\geq 10$ & 0.3 & $\geq 1$ & & $\geq 1$ & & $\geq 1$ & & $\geq 1$ & 1.0 & $\geq 1$ & & $\geq 1$ \\
\hline Obst & tion & & & & & & & & & & & & & \\
\hline$N$ & 1 & & & & 1 & & 2 & & 4 & & 2 & & & \\
\hline$\%$ & 0.9 & $\geq 1$ & & N/A & 1.6 & $\geq 1$ & 3.0 & $\geq 1$ & 2.2 & $\geq 1$ & 1.9 & $\geq 1$ & & $\geq 0.1$ \\
\hline Flatu & & & & & & & & & & & & & & \\
\hline$N$ & & & & & & & & & 1 & & 4 & & & \\
\hline$\%$ & & $\geq 0.1$ & & N/A & & $\geq 1$ & & N/A & 0.6 & N/A & 3.9 & $\geq 1$ & & $\geq 0.1$ \\
\hline
\end{tabular}


Table 4 continued

\begin{tabular}{|c|c|c|c|c|c|c|c|c|c|c|c|c|c|c|}
\hline & \multicolumn{2}{|l|}{ TPM } & \multicolumn{2}{|l|}{ LEV } & \multicolumn{2}{|l|}{ PGB } & \multicolumn{2}{|l|}{ ZNS } & \multicolumn{2}{|c|}{ OXC(ER) } & \multicolumn{2}{|c|}{ LCM } & \multicolumn{2}{|l|}{ ESL } \\
\hline & Obs. & $\mathrm{SmPC}$ & Obs. & $\mathrm{SmPC}$ & Obs. & $\mathrm{SmPC}$ & Obs. & $\mathrm{SmPC}$ & Obs. & $\mathrm{SmPC}$ & Obs. & $\mathrm{SmPC}$ & Obs. & $\mathrm{SmPC}$ \\
\hline \multicolumn{15}{|c|}{ Hepatobiliary disorders } \\
\hline \multicolumn{15}{|c|}{ Increase in liver enzymes } \\
\hline$N$ & & & 6 & & 1 & & 2 & & 6 & & 2 & & 2 & \\
\hline$\%$ & & $\geq 0.1$ & 1.6 & $\geq 0.1$ & 1.6 & $\geq 0.1$ & 3.0 & $\geq 1$ & 3.3 & $\geq 0.1$ & 1.9 & $\geq 0.1$ & 11.8 & $\geq 0.1$ \\
\hline \multicolumn{15}{|c|}{ Skin and subcutaneous tissue disorders } \\
\hline \multicolumn{15}{|c|}{ Hypersensitivity/pruritus } \\
\hline$N$ & & & 2 & & & & & & 1 & & 1 & & & \\
\hline$\%$ & & $\geq 1$ & 0.5 & $\geq 0.01$ & & $\geq 0.1$ & & $\geq 1$ & 0.6 & $\geq 0.001$ & 1.0 & $\geq 1$ & & $\geq 0.1$ \\
\hline \multicolumn{15}{|c|}{ Alopecia } \\
\hline$N$ & 1 & & 2 & & & & & & 2 & & 1 & & & \\
\hline$\%$ & 0.9 & $\geq 1$ & 0.5 & $\geq 0.01$ & & N/A & & $\geq 1$ & 1.1 & $\geq 1$ & 1.0 & N/A & & $\geq 0.1$ \\
\hline \multicolumn{15}{|c|}{ Musculoskeletal disorders } \\
\hline \multicolumn{15}{|c|}{ Myoclonia } \\
\hline$N$ & & & 1 & & & & 1 & & 2 & & & & & \\
\hline$\%$ & & $\geq 1$ & 0.3 & N/A & & $\geq 0.1$ & 1.5 & N/A & 1.1 & N/A & & $\geq 1$ & & N/A \\
\hline \multicolumn{15}{|c|}{ General disorders } \\
\hline \multicolumn{15}{|c|}{ Peripheral edema } \\
\hline$N$ & & & & & 4 & & & & 2 & & & & 1 & \\
\hline$\%$ & & N/A & & N/A & 6.5 & $\geq 1$ & & $\geq 1$ & 1.1 & N/A & & N/A & 5.9 & $\geq 0.1$ \\
\hline \multicolumn{15}{|c|}{ Total } \\
\hline$N$ & 109 & & 367 & & 61 & & 68 & & 183 & & 102 & & 17 & \\
\hline$\%$ & 100 & & 100 & & 100 & & 100 & & 100 & & 100 & & 100 & \\
\hline
\end{tabular}

$A D R$ adverse drug reaction, ESL eslicarbazepine, $L C M$ lacosamide, $L E V$ levetiracetam, N/A not available, Obs. observed, $O X C(E R)$ oxcarbazepine extended-release formulation, $P G B$ pregabalin, SmPC Summary of Product Characteristics, TPM topiramate, ZNS zonisamide

\section{Discussion}

\subsection{AED Usage and ADR Incidence}

Of the various AEDs of interest in this survey, OXC(ER) and LEV were most frequently used. To our knowledge, no study has so far investigated this selection of newer AEDs, but there are three different papers reporting on the nationwide prescription patterns of AEDs in Italy (data included until 2007), Norway (until 2009) and Germany (until 2010) $[13,29,30]$. Extracting the data related to the AEDs focused on in this survey also reveals the tendency towards LEV being the most frequently used, followed by OXC(ER), TPM, ZNS and PGB. LCM and ESL were the most recently approved AEDs, which is why no reliable data were available.

With regard to every first documented observation per patient in this evaluation, almost $90 \%$ were on polytherapy. Compared with the studies of Canevini et al. and Malerba et al. in which 22.5 and $21 \%$, respectively, of drug refractory patients were being managed on a single AED [30, 31], a proportion of $10.1 \%$ is small. However, in our survey only patients recently admitted to in-house treatment were included, for whom, other than severe epilepsy, the need for a complex therapy management, including administration of antiepileptic medication for acute use and the change in therapy by gradual cross-over of AEDs, can be assumed. By considering the calculated mean data for the length of stay, number of concomitant AEDs and AED load, defined as the sum of DDDs (Table 1), this assumption can be substantiated.

It is still a matter of debate if antiepileptic polymedication compared with monotherapy is generally associated with more frequent ADRs. The correlation between AED toxicity and total drug load rather than the number of concomitant AEDs is also still under discussion [31-34]. In this survey, both factors were significantly associated with a more frequent occurrence of ADRs, whilst also both were strongly correlated with each other. However, in view of the numerical extent of association, the total number of AEDs seemed to be of greater impact. The reasons for this can be manifold, including the absence of a rigid dosing scheme, a gradual cross-over of AEDs, and the value of DDD as an imperfect measure of drug exposure itself [15, $31,35]$. Testing for serum concentration-dependent tolerability was also considered for this survey, but ultimately rejected as therapeutic drug monitoring of the newer AEDs often was applied in selected cases only [36] and, therefore, corresponding serum concentrations were not available in every documented data set. 
The overall incidence of ADRs was calculated as $56.6 \%$, based on 318 patients for whom adverse reactions were documented. With regard to the method of assessment and the investigated patient population, this result corresponds well with that of other studies. Canevini et al., who also analyzed patients with drug-resistant epilepsy at tertiary referral centers, identified ADRs in $36.5 \%$ of patients, based on spontaneous reporting, compared with 95.5\% when a validated screening questionnaire was used [31]; similar results were summarized in a review of Perucca and Gilliam [37]. Considering that the detection of ADRs in clinical routine is derived from spontaneous reporting complemented by medical examination and lab diagnostics, and in view of the findings by Baker et al., which indicate a prevalence underestimation of ADRs when based on spontaneous reporting versus overestimation when using checklists, the extent of prevalence in this survey can be considered plausible for a real-life hospital setting [38].

Concerning the overall tolerability, LEV emerged as best tolerated, which, similarly, was reported by Cramer et al. [28]. This may be a reason for it being first recommended and therefore frequently used, as also indicated by the high number of patients under LEV in this survey. The calculated RRs of ADR occurrence for each AED compared with LEV varied between 1.31 and 2.30. But these values should be treated with caution; for the evaluation, only the total number of possibly related ADRs was taken into account, and not the type nor the clinical relevance of the ADR, nor other tolerability influencing factors. The impact of associated ADRs can be very different, which is why by using this kind of RR calculation only the overall tolerability can be estimated and has to be reviewed in every single case [31, 37]. Furthermore, all patients were preselected due to reallife conditions, and the total number of patients treated with particular AEDs varied widely, which in itself may have had an impact on the estimated RR.

An interesting finding of this survey was the rather high proportion of off-label use concerning maximum recommended daily dosage (Table 3). So far, there are not many studies investigating off-label use by dose in drug resistant epilepsy. One study by Franco et al. focused on this question by means of a diagram, showing proportions of off-label use of between 0 and $25 \%$ [39]. The values in our survey ranged from $6.4 \%$ for TPM up to $64.7 \%$ for ESL. By comparing the calculated RR for each AED used offlabel to its application as recommended by the SmPC, no considerable change of ADR occurrence was seen. However, the documented extent of off-label use showed an obvious relevance for clinical practice, indicating the need of further investigations on potential risks and benefits to alleviate physicians' and patients' uncertainty whilst using a drug out of its specification [39].
As already mentioned, antiepileptic therapy often means a balancing act between optimizing therapeutic outcome and running the risk of ADRs [6-8, 14, 15, 31, 37, 40-42]. It is therefore important to be aware of the side effect profiles of every considered AED in order to choose the best therapy option for every patient. The comparison of incidences of ADRs with possible causality in relation to the information mentioned in the SmPC, which, to our knowledge, was first performed in this survey, is very valuable to provide a supplementary assessment of particular risk. Even though, SmPC data present a very rough estimate for ADR frequency by using categories differing by one power of ten only, e.g., $\geq 0.1 \%$ for an uncommon and $\geq 10 \%$ for a very common occurrence, for some of the documented ADRs, a probable underestimation was determined. For example, in the case of cognitive impairment related to TPM or electrolyte imbalance under therapy with a CA inhibitor (i.e., TPM, ZNS) or dibenzazepine anticonvulsants (i.e., OXC, ESL), the discrepancy was particularly apparent.

It is a well known fact that the detection of specific ADRs can be influenced by physicians' expectations as to the likelihood of occurrence $[8,31]$. Therefore, it cannot be excluded that applied targeted testing, such as close control of lab values, will cause a detection bias.

TPM and ZNS are known as inhibitors of CA, which has a considerable share in regulating the acid-base balance and therefore influences the electrolyte status. In this survey, low potassium levels $(<3.6 \mathrm{mEq} / \mathrm{L})$ were assessed for 11 and nine patients on TPM and ZNS (10.1 and $13.2 \%)$, respectively, although the $\mathrm{SmPC}$ of both drugs mention this to be an uncommon occurrence $(\geq 0.1$ and $<1 \%)[17,20]$. A similar result for TPM was found in a systematic review by Dell'Orto et al., indicating hypokalemia as concomitant with metabolic acidosis for $10 \%$ of the cases [43]. To our knowledge, there are no comparable investigations referring to potassium levels under ZNS treatment, but a study by Mirza et al. indicated similar inhibitor potency to CA isoforms by TPM and ZNS, both inducing renal tubular acidosis [44]. Therefore, it seems plausible to detect an also increased frequency of hypokalemia under ZNS. Further investigations are definitely necessary to verify these results, but until then, the potential risk of $\mathrm{CA}$ inhibitors should be considered, particularly in patients with comorbidity or co-medication influencing electrolyte balance.

The same applies to treatment regimes with OXC(ER) or ESL, for which a higher incidence of hyponatremia, compared with SmPC data, was documented [21, 23]. As possible reasons, the previously mentioned detection bias or other influencing factors, like vomiting, diuretic or psychotropic medication, heart or kidney insufficiency, etc., should be also taken into account. Furthermore, the varying reference values applied for the definition of 
hyponatremia in different studies (here $<135 \mathrm{mEq} / \mathrm{L}$ ) and the highly selected patient population in this survey should be considered. Apart from this, there are many studies mentioning the frequency of decreased sodium serum levels in about $10-30 \%$ of the patients under OXC treatment, which in turn substantiates an assumed higher risk [45-50]. At the time of approval, ESL was promoted as bearing a lower hyponatremia risk compared with OXC. However, studies by Ley et al. and Gupta et al. could not substantiate this claim [51, 52]. In our survey, almost all patients with ESL stopped OXC(ER) because of decreased sodium levels prior. Therefore, the previous experience of hyponatremia could be an explanation for the high incidence even under ESL. But interesting in this context, data concerning hyponatremia mentioned in the SmPC have, since approval, been adjusted to a common frequency $(\geq 1$ and $<10 \%$ ), therefore, indicating the same risk as for OXC(ER), by now [23, 53].

With regard to cognitive impairment (e.g., psychomotor slowing, difficulty with concentration/attention, difficulty with memory, speech or language problems, particularly word-finding difficulties), this is a well described problem in patients on TPM [42, 54-59]. Being aware of that, neuropsychological testing and retesting (investigating cognitive processing, memory, language) are more often applied in conjunction with TPM therapy, as for example, recommended by Lee et al. [60]. This may have induced an overestimation of the particular risk in this survey, since cognitive impairment is also known to be influenced by seizure frequency and an increased number and dosage of AEDs [56]. However, a review by Mula, investigating the evidence of cognitive impairment under TPM, established that approximately $10 \%$ of the patients experienced cognitive problems [58]. Of these, as also confirmed in our survey, speech problems mainly concerning verbal fluency were the most prominent [58,61], a fact, which should be considered in individual treatment plans, especially for patients actively working or studying.

In conclusion, the results of this survey show that a systematic evaluation of inpatient data allows for even more information to be gained than could be extracted from clinical trials or SRS. Therefore, this kind of surveillance can provide a decisive contribution to future adjustments of risk data, applied to align approval data with real-life experience, which is an ongoing process, as the comparison of SmPC data from 2011 and 2015 reflects [17-23, 53, 62-67].

\subsection{Methodological Considerations}

Within this project, data were collected weekly by a pharmacist as part of the Consultants' ward rounds. It cannot be excluded that short-stay patients were missed, which could have biased the selection of patients towards more complex therapies. For this reason and to avoid time-consuming redocumentation of paper notes, the implementation of electronic patient records is to be recommended. For ADR documentation, no standardized questionnaire was used in this survey, which may have underrated some ADR incidences. However, by using this method, the ADR assessment remained as close to clinical routine as possible, and is therefore assumed to reflect the problems and concerns of practical relevance. A challenge, which is inherent in the system, is the real-life data assessment itself. Influencing factors, such as dose adjustment, change of therapy regime, co-morbidity or concomitant drug use, etc., do not follow a precise study plan under these conditions. Thus, the causality assessment and calculation of RRs concerning ADR are only methodical approaches to deal with these data, and the corresponding results should be judged in context and treated with caution. Due to this, not every pointed question of scientific interest can be proven or rejected. Moreover, neither the applied method nor all of the results can be translated to patients treated at primary care level or those being well controlled concerning seizure frequency and tolerability. But by this approach, treatment issues relevant to all patients can be identified and used as guidance for further investigation.

The major advantage of this method lies in the prospectively orientated full assessment of patients. It provides reliable application data, and the rather long-term observation period, the accumulation of medical information and the opportunity of monitoring progress, encourage the evaluation of causal relations between ADRs and suspected drugs.

\section{Conclusion}

For patients depending on lifelong treatment, optimized therapies adapted to individual needs are of great importance. For this purpose, established expertise in the advantages and disadvantages of each drug is indispensable. It has been shown that during inpatient treatment, valuable data are generated. A systematic assessment and continuous evaluation of these data can constitute a chance for perpetual risk and treatment evaluation under real-life conditions and therefore support individualized therapy management. Accordingly, even if this approach may need more methodological reasoning, it would certainly provide a new quality of drug surveillance.

Acknowledgments We would like to express our gratitude to Prof. T.W. May, Gesellschaft für Epilepsieforschung Bielefeld, for his encouragement and professional support with statistical analysis.

Author contributions Annika Hilgers was involved in the conception of this study, collected all relevant data prospectively, developed the internal database, ran the analyses, and drafted the 
manuscript. Marion Schaefer was involved in the conception of this study and reviewed and provided critical revisions to the manuscript.

\section{Compliance with Ethical Standards}

Ethical approvals For this type of study, ethical approval was not required. Data were collected as part of clinical routine and the use of patients' medical records was in accordance with the Gesundheitsdatenschutzgesetz (GDSG NRW, German law of healthcare data protection). The study was performed in accordance with the ethical standards of the Declaration of Helsinki.

Informed consent For this study, no informed consent was collected from the patients as all information was extracted from routine medical records and used anonymously.

Conflict of interest Annika Hilgers and Marion Schaefer have no conflicts of interest.

Funding Annika Hilgers has received third-party funds within a $\mathrm{Ph} . \mathrm{D}$. project from the Bundesinstitut für Arzneimittel und Medizinprodukte (BfArM), the German drug regulatory authority, between 2008 and 2010, which enabled performance of the data collection prospectively.

Open Access This article is distributed under the terms of the Creative Commons Attribution-NonCommercial 4.0 International License (http://creativecommons.org/licenses/by-nc/4.0/), which permits any noncommercial use, distribution, and reproduction in any medium, provided you give appropriate credit to the original author(s) and the source, provide a link to the Creative Commons license, and indicate if changes were made.

\section{References}

1. WHO-World Health Organisation. WHO Policy perspectives on medicines: Pharmacovigilance: ensuring the safe use of medicines. 2004. http://apps.who.int/medicinedocs/pdf/s6164e/s6164e.pdf. Accessed 17 Dec 2015.

2. Waller PC, Bahri P. Regulatory pharmacovgilance in the EU. In: Mann RD, Andrews E, editors. Pharmacovigilance. Chichester: Wiley; 2002. p. 183-94.

3. Hazell L, Shakir SAW. Under-reporting of adverse drug reactions: a systematic review. Drug Saf. 2006;29(5):385-96.

4. Lopez-Gonzalez E, Herdeiro MT, Figueiras A. Determinants of under-reporting of adverse drug reactions: a systematic review. Drug Saf. 2009;32(1):19-31.

5. van der Heijden PG, van Puijenbroek EP, van Buuren $S$, van der Hofstede JW. On the assessment of adverse drug reactions from spontaneous reporting systems: the influence of under-reporting on odds ratios. Stat Med. 2002;21(14):2027-44.

6. Gilliam FG. Optimizing health outcomes in active epilepsy. Neurology. 2002;58(Suppl. 5):9-19.

7. Langfitt J, Meador K. Want to improve epilepsy care? Ask the patient. Neurology. 2004;62:6-7.

8. Sander JW. Ultimate success in epilepsy-the patient's perspective. Eur J Neurol. 2005;12(Suppl. 4):3-11.

9. Toledano R, Gil-Nagel A. Adverse effects of antiepileptic drugs. Semin Neurol. 2008;28(3):317-27.

10. Alexandre V Jr, Capovilla G, Fattore C, Franco V, Gambardella A, Guerrini R, La Briola F, Ladogana M, Rosati E, Specchio LM,
Striano S, Perucca E, SOPHIE Study Group. Characteristics of a large population of patients with refractory epilepsy attending tertiary referral centers in Italy. Epilepsia. 2010;51(5):921-5.

11. Fisher RS, Vickrey BG, Gibson P, Hermann B, Penovich P, Scherer A, Walker S. The impact of epilepsy from the patient's perspective. Descriptions and subjective perceptions. Epilepsy Res. 2000;41(1):39-51.

12. Johannessen Landmark C, Rytter E, Johannessen SI. Clinical use of antiepileptic drug at a referral centre for epilepsy. Seizure. 2007; 16:356-64.

13. Johannessen Landmark C, Fossmark H, Larsson PG, Rytter E, Johannessen SI. Prescription patterns of antiepileptic drugs in patients with epilepsy in a nation-wide population. Epilepsy Res. 2011;95:51-9.

14. Johannessen Landmark C, Johannessen SI. Safety aspects of antiepileptic drugs-focus on pharmacovigilance. Pharmacoepidemiol Drug Saf. 2012;21:11-20.

15. Patsalos PN, Berry DJ, Bourgeois BFD, Cloyd JC, Glauser TA, Johannessen SI, Leppik I, Tomson T, Perucca E. Antiepileptic drugs - best practice guidelines for therapeutic drug monitoring: a position paper by the Subcommission on Therapeutic Drug Monitoring, ILAE Commission on Therapeutic Strategies. Epilepsia. 2008;49(7):1239-76.

16. Uppsala Monitoring Centre. The use of the WHO-UMC system for standardized case causality assessment. 2012. http://www. who-umc.org/Graphics/26649.pdf. Accessed 28 Jan 2015.

17. Summary of Product Characteristics: Topamax, Janssen-Cilag GmbH; 2014. http://www.fachinfo.de. Accessed 20 May 2015.

18. Summary of Product Characteristics: Keppra, UCB Pharma GmbH; 2014. http://www.fachinfo.de. Accessed 20 May 2015.

19. Summary of Product Characteristics: Lyrica, Pfizer Ltd; 2014. http://www.fachinfo.de. Accessed 20 May 2015.

20. Summary of Product Characteristics: Zonegran, Esai GmbH; 2013. http://www.fachinfo.de. Accessed 20 May 2015.

21. Summary of Product Characteristics: Apydan extend, Desitin Arzneimittel GmbH; 2014. http://www.fachinfo.de. Accessed 20 May 2015.

22. Summary of Product Characteristics: Vimpat, UCB Pharma $\mathrm{GmbH}$; 2014. http://www.fachinfo.de. Accessed 20 May 2015.

23. Summary of Product Characteristics: Zebinix, Bial-Portela \& Ca, SA; 2014. www.fachinfo.de, Accessed 20 May 2015.

24. Deutsche Gesellschaft für Epileptologie e.V. Empfehlungen der Deutschen Gesellschaft für Epileptologie (DGfE) zur medikamentösen Behandlung fokaler Epilepsien im Erwachsenenalter, ergänzend zu den Leitlinien „Erster epileptischer Anfall und Epilepsien im Erwachsenenalter" der Deutschen Gesellschaft für Neurologie (DGN) von 2012. 2013. https://www.dgfe.info/ cweb2/cgi-bin-noauth/cache/VAL_BLOB/5038/5038/1355/Thera pieempfehlungen $\% 20$ Fokale\%20Epilepsien\%20DGfE\%202505 13-2.pdf. Accessed 28 Jan 2016.

25. Deutsche Gesellschaft für Neurologie. Erster epileptischer Anfall und Epilepsien im Erwachsenenalter. 2012. http://www.dgn.org/ leitlinien/11-leitlinien-der-dgn/2302-11-1-2012-ersterepileptischer-anfall-und-epilepsien-im-erwachsenenalter. Accessed 28 Jan 2016.

26. Glauser T, Ben-Menachem E, Bourgeois B, Cnaan A, Guerreiro C, Kälviäinen R, Mattson R, French JA, Perucca E, Tomson T, For the ILAE Subcommission on AED Guidelines. Updated ILAE evidence review of antiepileptic drug efficacy and effectiveness as initial monotherapy for epileptic seizures and syndromes. Epilepsia. 2013;54(3):551-63.

27. NICE-National Institute for Health and Care Excellence Guidelines. Epilepsies: diagnosis and management. 2012. http:// www.nice.org.uk/guidance/cg137/chapter/appendix-e-pharmacolo gical-treatment\#appendix-e-pharmacological-treatment. Accessed 28 Jan 2016. 
28. Cramer JA, Steinborn B, Striano P, Hlinkova L, Bergmann A, Bacos I, Baukens C, Buyle S. Non-interventional surveillance study of adverse events in patients with epilepsy. Acta Neurol Scand. 2011;124(1):13-21.

29. Fritze J. Psychopharmaka-Verordnungen: Ergebnisse und Kommentare zum Arzneiverordnungsreport 2011. Psychopharmakotherapie. 2011;18:245-56.

30. Malerba A, Ciampa C, De Fazio S, Fattore C, Frassine B, La Neve A, Pellacani S, Specchio LM, Tiberti A, Tinuper P, Perucca E. Patterns of prescription of antiepileptic drugs in patients with refractory epilepsy at tertiary referral centres in Italy. Epilepsy Res. 2010;91:273-82.

31. Canevini MP, De Sarro G, Galimberti CA, Gatti G, Licchetta L, Malerba A, Muscas G, La Neve A, Striano P, and Perucca E, On behalf of the SOPHIE Study Group. Relationship between adverse effects of antiepileptic drugs, number of coprescribed drugs, and drug load in a large cohort of consecutive patients with drug-refractory epilepsy. Epilepsia. 2010;51(5):797-804.

32. Deckers CLP. Over treatment in adults with epilepsy. Epilepsy Res. 2002;52:43-52.

33. Louis EKS. Truly "Rational" polytherapy: maximizing efficacy and minimizing drug interactions, drug load, and adverse effects. Curr Neuropharmacol. 2009;7(2):96-105.

34. Lammers MW, Hekster YA, Keyser A, Meinardi H, Renier WO, van Lier H. Monotherapy or polytherapy for epilepsy revisited: a quantitative assessment. Epilepsia. 1995;36:440-6.

35. Perucca E, Beghi E, Dulac O, Shorvon S, Tomson T. Assessing risk to benefit ratio in antiepileptic drug therapy. Epilepsy Res. 2000;41:107-39.

36. Striano S, Striano P, Capone D, Pisanti F. Limited place for plasma monitoring of new antiepileptic drugs in clinical practice. Med Sci Monit. 2008;14(10):173-8.

37. Perucca P, Gilliam FG. Adverse effects of antiepileptic drugs. Lancet Neurol. 2012;11:792-802.

38. Baker GA, Camfield C, Camfield P, Cramer JA, Elger CE, Johnson AL, Martins da Silva A, Meinardi H, Munari C, Perucca E, Thorbecke R. Commission on outcome measurement in epilepsy, 1994-1997: final report. Epilepsia. 1998;39(2):213-23.

39. Franco V, Canevini MP, Capovilla G, De Sarro G, Galimberti CA, Gatti G, Guerrini R, La Neve A, Rosati E, Specchio LM, Striano S, Tinuper P, Perucca E. Off-label prescribing of antiepileptic drugs in pharmacoresistant epilepsy: a cross-sectional drug utilization study of tertiary care centers in Italy. CNS Drugs. 2014;28(10):939-49.

40. Gilliam FD. What we dont't learn from clinical trials in epilepsy. Epilepsia. 2003;44(Suppl. 7):51-4.

41. Gilliam FD. Epilepsy-success in clinical practice: translating trials to practice. Eur J Neurol. 2005;12(Suppl. 4):22-9.

42. Perucca $P$, Meador KJ. Adverse effects of antiepileptic drugs. Acta Neurol Scand. 2005;112(Suppl. 181):30-5.

43. Dell'Orto VG, Belotti EA, Goeggel-Simonetti B, Simonetti GD, Ramelli GP, Bianchetti MG, Lava SAG. Metabolic disturbances and renal stone promotion on treatment with topiramate: a systematic review. BJCP. 2013;77(6):758-64.

44. Mirza NS, Alfirevic A, Jorgensen A, Marson AG, Pirmohamed M. Metabolic acidosis with topiramate and zonisamide: an assessment of its severity and predictors. Pharmacogenet Genomics. 2011;21:297-302.

45. Lin $\mathrm{CH}$, Lu CH, Wang FJ, Tsai MH, Chang WN, Tsai NW, Lai SL, Tseng YL, Chuang YC. Risk factors of oxcarbazepine-induced hyponatremia in patients with epilepsy. Clin Neuropharmacol. 2010;33(6):293-6.

46. Besi E, Boniface DR, Cregg R, Zakrzewska JM. Comparison of tolerability and adverse symptoms in oxcarbazepine and carbamazepine in the treatment of trigeminal neuralgia and neuralgiform headaches using the Liverpool Adverse Events Profile (AEP). J Headache Pain. 2015;16:81-7.

47. Buggy Y, Layton D, Fogg C, Shakir SAW. Safety profile of oxcarbazepine: results from a prescription-event monitoring study. Epilepsia. 2010;51(5):818-29.

48. Dong X, Leppik IE, White J, Rarick J. Hyponatremia from oxcarbazepine and carbamazepine. Neurology. 2005;65(12):1976-8.

49. Kim YS, Kim DW, Jung KH, Lee ST, Kang BS, Byun JI, Yeom JS, Chu K, Lee SK. Frequency of and risk factors for oxcarbazepine-induced severe and symptomatic hyponatremia. Seizure. 2014;23:208-12.

50. Ortenzi A, Paggi A, Foschi N, Sabbatini D, Pistoli E. Oxcarbazepine and adverse events: impact of age, dosage, metabolite serum concentrations and concomitant antiepileptic therapy. Funct Neurol. 2008;23(2):97-100.

51. Gupta DK, Bhoi SK, Kalita J, Misra UK. Hyponatremia following esclicarbazepine therapy. Seizure. 2015;29:11-4.

52. Ley M, Principe A, Jiménez-Conde J, Rocamora R. Assessing long-term effects of eslicarbazepine acetate on lipid metabolism profile, sodium values and liver function tests. Epilepsy Res. 2015;115:147-52.

53. Summary of Product Characteristics: Zebinix, Bial-Portela \& $\mathrm{Ca}$, SA; 2010. http://www.fachinfo.de. Accessed 14 Nov 2011.

54. Arif H, Buchsbaum R, Weintraub D, Pierro J, Resor SR Jr, Hirsch LJ. Patient-reported cognitive side effects of antiepileptic drugs: predictors and comparison of all commonly used antiepileptic drugs. Epilepsy Behav. 2009;14:202-9.

55. Kockelmann E, Elger CE, Helmstaedter C. Significant improvement in frontal lobe associated neuropsychological functions after withdrawal of topiramate in epilepsy patients. Epilepsy Res. 2003;54:171-8.

56. Loring DW, Marino S, Meador KJ. Neuropsychological and behavioral effects of antiepilepsy drugs. Neuropsychol Rev. 2007;17:413-25.

57. Loring DW, Williamson DJ, Meador KJ, Wiegand F, Hulihan J. Topiramate dose effects on cognition. A randomized doubleblind study. Neurology. 2011;76:131-7.

58. Mula M. Topiramate and cognitive impairment: evidence and clinical implications. Ther Adv Drug Saf. 2012;3(6):279-89.

59. Ojemann LM, Ojemann GA, Dodrill CB, Crawford CA, Holmes MD, Dudley DL. Language disturbances as side effects of topiramate and zonisamide therapy. Epilepsy Behav. 2001;2:579-84.

60. Lee S, Sziklas V, Andermann F, Farnham S, Risse G, Gustafson M, Gates J, Penovich P, Al-Asmi A, Dubeau F, Jones-Gotman M. The effects of adjunctive topiramate on cognitive function in patients with epilepsy. Epilepsia. 2003;44(3):339-47.

61. Sommer BR, Mitchell EL, Wroolie TE. Topiramate: effects on cognition in patients with epilepsy, migraine headache and obesity. Ther Adv Neurol Disord. 2013;6(4):211-27.

62. Summary of Product Characteristics: Topamax, Janssen-Cilag GmbH; 2011. http://www.fachinfo.de. Accessed 14 Nov 2011.

63. Summary of Product Characteristics: Keppra, UCB Pharma GmbH; 2011. http://www.fachinfo.de, Accessed 14 Nov 2011.

64. Summary of Product Characteristics: Lyrica, Pfizer Ltd; 2011. http://www.fachinfo.de, Accessed 14 Nov 2011.

65. Summary of Product Characteristics: Zonegran, Esai GmbH; 2011. http://www.fachinfo.de. Accessed 14 Nov 2011.

66. Summary of Product Characteristics: Apydan extend, Desitin Arzneimittel GmbH; 2010. http://www.fachinfo.de. Accessed 14 Nov 2011.

67. Summary of Product Characteristics: Vimpat, UCB Pharma GmbH; 2011. http://www.fachinfo.de. Accessed 14 Nov 2011. 